Original Research

\title{
Determinants of Drug Adherence on Grade Two and Three Patients with Hypertension
}

\author{
Riza Fikriana', Shrimarti Rukmini Devy', Ahsan Ahsan² and Al Afik ${ }^{\mathbf{3}}$ \\ ${ }^{1}$ Faculty of Public Health, Universitas Airlangga, East Java, Indonesia \\ 2 Faculty of Medicine, Brawijaya University, East Java, Indonesia \\ ${ }^{3}$ Faculty of Medicine and Health Science, University of Muhammadiyah Yogyakarta, Indonesia
}

\begin{abstract}
Introduction: Compliance for taking medication has become an important activity for patients with hypertension. Compliance is needed to control blood pressure and prevent complications. The purpose of this study was to analyse determinant drug adherence on grade two and three patients with hypertension.
\end{abstract}

Methods: The study design was a descriptive survey using a cross-sectional approach. the sample was 225 patients with hypertension grade two and three. The sampling technique was done using a multistage random sampling technique. The coping strategy is the independent variable and drug adherence is the dependent variable. The research instrument was in the form of a questionnaire which consisted of demographic, coping strategy used, COPE inventory scale questionnaire, and drug adherence using the Hypertension Self-Care Profile questionnaire. Data analysis was performed using the Pearson test and linear regression.

Results: The results showed that patient adherence in taking medicine was $51.1 \%$ in the medium category. Factors influencing the adherence were ages ( $\mathrm{p}$-value: 0.002 ), return to religion ( $p$-value: 0.011 ), gender ( $p$-value: 0.016 ) and suppressing competition activities ( $\mathrm{p}$-value: 0.063 ).

Conclusion: Age, gender, return to religion and suppressing competition activities influence the taking of medication in patients with grade two and grade three hypertension. Strengthening coping strategies with transporting to coping emotions is very important and will affect drug adherence in patients with grade two and grade three hypertension.

\section{ARTICLE HISTORY}

Received: December 06, 2019

Accepted: December 30, 2019

\section{KEYWORDS}

coping strategic; drug adherence; hypertension

\section{CONTACT}

\section{Riza Fikriana}

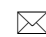

riza fikriana@stikeskepanjenpemkabmalang.ac.id

$\equiv$ Faculty of Public Health, Universitas Airlangga East Java, Indonesia

Cite this as: Fikriana, R., Devy, S. R., Ahsan, A.. \& Afik, A. (2019). Determinants of Drug Adherence on Grade Two and Three Patients with Hypertension. Jurnal Ners, 14(2), 193-198.

doi:http://dx.doi.org/10.20473/in.v14i2.16531

\section{INTRODUCTION}

The development of the disease is now shifting from infectious diseases to non-communicable conditions. While the problem of infectious diseases has not been resolved, the prevalence of non-communicable diseases continues to increase (Atiim, G., et al, 2015). Hypertension is a non-communicable disease in which numbers continue to grow (Bell Kayce et al., 2015; Bhagani, S., et al., 2018). In Indonesia, the development of hypertension prevalence continues to grow throughout the year. The results of the Riskesdas conducted by the Ministry of Health of the Republic of Indonesia found that the incidence of hypertension from 2013 to 2018 rose sharply from $25.8 \%$ to $34.1 \%$ (Kemenkes RI, 2018). The increase should be a concern given the increase of complications due to hypertension, such as cardiovascular disease, stroke and kidney failure (Fikriana, R., 2016; Fikriana, R., et al, 2018).

One of the causes of the increased risk of hypertension complications is due to non-compliance with hypertension treatment. Non-compliance with treatment will cause uncontrolled blood pressure and lead to the risk of complications (Fikriana, R., 2018). Studies show that $51.6 \%$ of hypertension patients taking antihypertensive drugs include in unchecked hypertension (Borghi, C., et al., 2016). Blood pressure control is also deficient, at $22.3 \%$ (Shafi, S. T.,et al, 2017). As a result, the increase of uncontrolled hypertension is correlated with an increased risk of heart disease (Borghi, C., et al., 2016). Hypertension 
classification are optimal blood pressure, normal blood pressure, high-normal blood pressure, grade one hypertension, grade two hypertension, grade three hypertension, isolated systolic hypertension, white-coat hypertension and masked hypertension. In patients with grade two and three, hypertension has a very high risk of complications and organ damage (Indonesian Society of Hypertension, 2019; Bhagani, S., et al, 2018).

The results of the study of adherence showed that $32.3 \%$ did not take medication regularly, $13.3 \%$ did not take medicine, and $54.4 \%$ take medicine daily. The reasons for not taking medicine are because they feel healthy (59.8\%), are not routinely going to health service facilities (31.3\%), taking traditional medicine (14.5\%), often forgetting (11.5\%), not being able to buy drugs regularly $(8.1 \%)$, cannot stand the side effects of drugs (4.5\%), medications do not exist in health care facilities $(2.0 \%)$ and others $(12.5 \%)$ (Borghi, C., et al., 2016). Patients with hypertension who take antihypertensive drugs for controlling blood pressure slightly increased by $32.3 \%$. However, this value is also still classified as very low. Low blood pressure control is positively correlated with increasing age, body mass index and occupational status (Shafi, S. T.,et al, 2017; (Fikriana, R., 2016; Fikriana, R., et al, 2018).

In a situation that is considered as stressful and requires an effort to overcome it, coping will have an effect on a person. Coping strategies aim to manage stressors or regulate emotions arising from stressful situations (Biggs, A., 2017; Nursalam, 2017). Coping strategies are related to a person's quality of life. Coping strategies that are positively associated with the right psychosocial environment and which produce good physical health will improve the quality of life of a person (Hernández-ledesma, A. L.,et al, 2018). Situational assessment and conditions that occur will affect how coping strategies are effective in dealing with stress and be able to influence one's decision to perform certain behaviours. Based on the transactional theory, coping is a continuous cognitive change and a person's behavioural effort in managing the existence of both internal and external demands that are judged to be beyond one's ability. Coping is process-oriented, dynamic, and is done consciously and directed (Biggs, A., 2017; Nursalam, 2017).

Several factors influence the behaviour of hypertensive sufferers towards medication adherence. Knowledge about medication, frequency and dosage of drugs has a role in influencing adherence (Ramli, A., et al, 2012). The aim of the research was to analyse the determinant drug adherence on grade two and three hypertension patients.

\section{MATERIALS AND METHODS}

This study was a cross-sectional design. The study was conducted from July to August 2019 in the Malang district, Indonesia. The sample was 225 people with hypertension. Inclusion criteria: 1) hypertension patients with grade two and grade three hypertension criteria, 2) aged more than 30 years old. The exclusion criteria: 1) The patient is getting treatment in hospital, 2) patients were in the total and partial dependency level category. The sampling technique used multistage random sampling. This sampling technique uses three stages. The first step is to determine the five sub-districts in Malang Regency by simple random sampling. The second step was to determine each of the one regions from one district by simple random sampling. The third stage was to determine hypertension patients from each region by simple random sampling. Variables in this study were coping strategic (independent variable) and drug adherence (dependent variable).

The instrument used was a questionnaire. The questionnaire covers the demographic characteristics of the respondents, which include age, gender, family history of hypertension and a long duration of hypertension. The patient coping questionnaire was measured by examining problemfocused coping consisting of active coping, planning, restraint, suppression of competing activities, seeking instrumental and informational social support and reviewing emotion-focused coping consisting of positive reinterpretation, return to religion and seeking emotional, social support. The coping questionnaire was adopted from the COPE Inventory scale questionnaire (Carver, C. S, 2013). Respondents answered the coping questionnaire choices using a Likert scale consisting of four answer choices that are never, sometimes, often and always. The data scale used numeric data. The drug adherence questionnaire was adopted from the Hypertension Self-Care Profile (HBP SCP) questionnaire regarding adherence to taking antihypertensive medication ( Han, et al, 2014). The drug adherence questionnaire used a Likert scale of four answer choices that are never, sometimes, often and always. The questionnaire was tested for validity and reliability, with a Cronbach alpha active coping value of 0.806 with four questions; planning value of 0.884 with four questions; restrain value of 0.700 with four questions; suppression of competing activities value of 0.737 with four questions; seeking instrumental and informational social support value of 0.921 with five questions; return to religion value of 0.884 with five questions; seeking social emotional social support value of 0.825 with five questions.

Prior to data collection, the researcher obtained informed consent for the study with each respondent. The researcher explains the purpose of the study, the benefits of the research and the procedure of conducting the research. Respondents who agreed to be involved in the research process must sign an informed consent sheet. Approval of research ethics has been carried out by the Health Research Ethics Committee of the Faculty of Nursing, Universitas Airlangga, Surabaya, No. 1468-KEPK. 
Data analysis of demographic characteristics, coping, and medication adherence characteristics variables were performed using frequency distribution. The data distribution is normal. To find out the relationship between demographic and coping characteristics with adherence to medication, use the Pearson test. Determinant drug adherence was analysed by using a linear regression test.

\section{RESULTS}

\section{Demographic Characteristics}

The demographic characteristics of people with hypertension are described in terms of age, sex, family history of hypertension and long duration of hypertension. Table 1 shows that the majority of respondents, $70.7 \%$ aged $56-65$ years and $3.1 \%$ aged 26 - 35 years. A total of $83.1 \%$ were female and the majority, namely $79.1 \%$ of respondents had no family history of hypertension. In addition, it was found that more than half the respondents, 64\% had hypertension for 1-3 years.

\section{Coping of Patients with Hypertension}

People with hypertension are described as problemfocused coping and emotion-focused coping which is divided into eight types of coping done by the patient. The results in Table 2 shows that planning, restraint, suppression of competing activities, positive reinterpretation and seeking emotional social support found that more than half of the respondents were in the poor category, namely $52.9 \%, 53.3 \%$, $54.2 \%, 52.9 \%$, and $54.2 \%$. Whereas in the sufficient category, coping has a percentage of more than half the respondents is active coping (53.8\%), seeking instrumental and informational social support (54.2\%) and return to religion (51.1\%). While coping is in a good category, all coping components are in a very low percentage of less than.

\section{Drug Adherence}

Analysis of the frequency distribution of drug administration are 74 people (32.9\%) low category, 115 people (51.1\%) medium category and 36 (16\%) is good enough.

\section{Relationship between Demographic and Coping Characteristics with Drug Adherence}

Trial analysis using the Pearson test according to table 3 obtained demographics and coping related to drug testing about type variables not related to drink or drug testing. Return to religion was the variable that was most strongly associated with taking medication meetings ( $\mathrm{r}=0.322)$.

Effects of Demographic Characteristics and Coping on Medication Adherence

Table 4 illustrates the results of the linear regression analysis of the variables that influence medication adherence. The results show that there are four variables that influence medication adherence, namely age, sex, suppression of competing activities and return to religion. The suppression of competing activities variable is retained by the model even though p-value> 0.05. These results indicate that coping strategies that are very influential on medication adherence in patients with grade 2 and grade 3 hypertension are emotion focused coping, especially return to religion and suppression of competing activities.

Table 1. Demographic Characteristics of Patients with Hypertension $(n=225)$

\begin{tabular}{lcc}
\hline \multicolumn{1}{c}{ Variable } & $\mathbf{n}$ & $\mathbf{\%}$ \\
\hline Age & & \\
$26-35$ years old & 7 & 3.1 \\
$36-45$ years old & 15 & 6.7 \\
$46-55$ years old & 34 & 15.1 \\
$56-65$ years old & 159 & 70.7 \\
$\quad>65$ years old & 10 & 4.4 \\
Gender & & \\
$\quad$ Male & 38 & 16.9 \\
Female & 187 & 83.1 \\
Family History & & \\
Yes & 47 & 20.9 \\
$\quad$ No & 178 & 79.1 \\
Long suffered & & \\
$\quad<1$ years & 50 & 22.2 \\
1 - 3 years & 144 & 64.0 \\
$>3$ years & 31 & 13.8 \\
\hline
\end{tabular}

Table 2. Frequency Distribution of Hypertension Patients' Coping Strategy $(n=225)$

\begin{tabular}{|c|c|c|}
\hline Variable & $\mathbf{n}$ & $\%$ \\
\hline \multicolumn{3}{|l|}{ Active coping } \\
\hline Less & 68 & 30.2 \\
\hline Enough & 121 & 53.8 \\
\hline Good & 36 & 16.0 \\
\hline \multicolumn{3}{|l|}{ Planning } \\
\hline Less & 119 & 52.9 \\
\hline Enough & 74 & 32.9 \\
\hline Good & 32 & 14.2 \\
\hline \multicolumn{3}{|l|}{ Restraint } \\
\hline Less & 120 & 53.3 \\
\hline Enough & 73 & 32.4 \\
\hline Good & 32 & 14.2 \\
\hline \multicolumn{3}{|c|}{$\begin{array}{l}\text { Suppression of competing } \\
\text { activities }\end{array}$} \\
\hline Less & 122 & 54.2 \\
\hline Enough & 77 & 34.2 \\
\hline Good & 26 & 11.6 \\
\hline \multicolumn{3}{|c|}{$\begin{array}{l}\text { Seeking instrumental and } \\
\text { informational social support }\end{array}$} \\
\hline Less & 70 & 31.1 \\
\hline Enough & 122 & 54.2 \\
\hline Good & 33 & 14.7 \\
\hline \multicolumn{3}{|c|}{ Positive reinterpretation } \\
\hline Less & 119 & 52.9 \\
\hline Enough & 84 & 37.3 \\
\hline Good & 22 & 9.8 \\
\hline \multicolumn{3}{|l|}{ Return to religion } \\
\hline Less & 84 & 37.3 \\
\hline Enough & 115 & 51.1 \\
\hline Good & 26 & 11.6 \\
\hline \multicolumn{3}{|c|}{ Seeking emotional social support } \\
\hline Less & 122 & 54.2 \\
\hline Enough & 71 & 31.6 \\
\hline Good & 32 & 14.2 \\
\hline
\end{tabular}


Table 3. Drug Adherence $(n=225)$

\begin{tabular}{lcc}
\hline \multicolumn{1}{c}{ Variable } & n & \% \\
\hline Drug Adherence & & \\
Low & 74 & 32.9 \\
Medium & 115 & 51.1 \\
Good & 36 & 16.0 \\
\hline
\end{tabular}

Table 4. Relationship between demographic characteristics and coping on drug adherence

\begin{tabular}{lcc}
\hline \multicolumn{1}{c}{ Variable } & \multicolumn{2}{c}{$\begin{array}{c}\text { Medication } \\
\text { adherence }\end{array}$} \\
& r & p-value \\
\hline Age & -0.132 & 0.047 \\
Gender & 0.023 & 0.730 \\
Family History & -0.131 & 0.050 \\
Long suffered & -0.129 & 0.054 \\
Active coping & 0.212 & 0.001 \\
Planning & 0.215 & 0.001 \\
Restraint & 0.207 & 0.002 \\
Suppression of competing & 0.295 & 0.000 \\
activities & & \\
Seeking instrumental and & 0.195 & 0.003 \\
informational social support & & \\
Positive reinterpretation & 0.170 & 0.011 \\
Return to religion & 0.322 & 0.000 \\
Seeking emotional social & 0.205 & 0.002 \\
support & & \\
\hline
\end{tabular}

Table 5. Linear Regression Analysis of Factors Affecting Drug Interactions

\begin{tabular}{|c|c|c|c|c|c|}
\hline Variable & $B$ & $S E$ & $\beta$ & $t$ & p* \\
\hline Constant & 1.363 & 0.247 & & 5.526 & 0.000 \\
\hline Age & $\begin{array}{c}- \\
0.639\end{array}$ & 0.200 & $\begin{array}{c}- \\
0.369\end{array}$ & $\begin{array}{c}- \\
3.204\end{array}$ & 0.002 \\
\hline Gender & 0.584 & 0.240 & 0.284 & 2.430 & 0.016 \\
\hline $\begin{array}{l}\text { Suppression } \\
\text { of competing } \\
\text { activities }\end{array}$ & 0.145 & 0.078 & 0.142 & 1.867 & 0.063 \\
\hline $\begin{array}{l}\text { Return to } \\
\text { religion }\end{array}$ & 0.182 & 0.071 & 0.200 & 2.575 & 0.011 \\
\hline
\end{tabular}

\section{DISCUSSION}

Hypertension is a significant risk factor for cardiovascular and kidney disease. Although treatment for hypertension is available, only about $25 \%$ of people with hypertension have control of their blood pressure. Effective management in patients with hypertension is recommended to assess the asymptomatic target organ damage and the risk of secondary causes. Management of hypertension depends not only on the level of blood pressure but also on the risk of cardiovascular disorders (Bhagani, S.,et al, 2018).

People with hypertension must be responsible for taking care of themselves every day. This treatment includes blood pressure monitoring, diet management, maintaining physical activity, maintaining weight, stress management and medication adherence. Appropriate treatment and lifestyle modification will be able to prevent and slow the occurrence of complications. Blood pressure that is not well controlled will contribute to heart and kidney disease. So that self-regulation to achieve the desired blood pressure level is very important (Visutyothin, Y., 2018).

The results of this study indicate that age, sex, return to religion and suppression of competing activities affect medication adherence in patients with grade 2 and grade 3 hypertension. These results illustrate that demographic characteristics also play a substantial role in adherence to taking drugs. Besides, these results also indicate that the coping strategy in the emotion-focused coping category is the coping strategy that is most influential on sufferers.

Age is the most potent variable influencing medication adherence. The results show that the younger generation tends to have a better level of adherence compared to old age. This is possible because young sufferers feel a higher threat to their disease, so they try to take the drug regularly to avoid excessive blood pressure. Whereas in elderly patients, long-term treatment that must be done is likely to have an impact on the emergence of boredom to consume drugs regularly. So that patients will prefer not to take medicine.

Gender also has an effect on medication adherence. Patients with hypertension who are female have better adhesion compared to men. Women tend to be more proactive in getting treatment for their condition. However, the results of other studies show that women have lower levels of medication adherence compared to men (Granger, B. B.,et al, 2009; Manteuffel, M., et al, 2017). This is possible because women experience more side effects that are felt due to the treatment received. So women decided to stop treatment (Manteuffel, M., et al, 2017).

This is also in line with other studies in which the suppression of competing activities affects the behaviour of sufferers who are under stress. Patients in stressful situations more often use coping strategies in the form of avoidance and rejection rather than finding positive aspects of the stressful event that they are experiencing (Orzechowska, A.,2013)

Return to religion reflects emotion-focused coping as a coping variable that influences medication adherence. This is supported by other studies that explain that emotion-focused coping is associated with the occurrence of dysmenorrhea (Nursalam, N., et al, 2018). Return to religion is an effort made to try and control the problems they are facing by multiplying prayers and getting closer to God. This strategy shows that the spiritual and religious dimensions of sufferers with chronic diseases become very important for their lives and affect the sufferer's representation of their health (Perricone, G.,et al, 2013). Spirituality has a significant relationship with disease prevention behaviour (Rohman.,et al, 2019).

Spiritual beliefs possessed by a patient suffering from a chronic illness has the potential to support or hinder a person's ability to care for himself (Drutchas, A., et al, 2014). Religious needs are strongly related to beliefs, beliefs and positive emotions towards God, where this is also related to an individual's 
interpretation of his illness (Büssing, A.,et al, 2015). In someone suffering from a chronic disease, religious needs are positively related to spiritual well-being and life satisfaction (Büssing, A., et al, 2013a). However, this is different from other research results where religious needs are not associated with high or low life satisfaction. However, this need refers more to the resources that are vital to them and relied on by them. This happens because of several underlying factors, namely their religious attitude, such as the attitude towards the strength of faith needed to survive in the difficult times they are going through. It is also based on their search for factors to find access to spiritual sources or sources of religiosity that may be useful to overcome the illness they experience which ultimately interprets their illness into something of value (Büssing, A.,et al, 2015).

In light of these conditions, the health worker has a duty to provide care to chronic patients, it is therefore necessary to conduct an assessment of their spiritual and religious needs. This is because the requirements for spirituality and religiosity play an essential role in the quality of life for sufferers (Büssing, A.,et al, 2010).

\section{CONCLUSION}

Several factors influence adherence to taking the medication in patients with grade two and grade three hypertension. Demographic characteristics, namely age and gender, and emotion-focused coping, namely religion and suppression of competing activities, have a significant effect on medication adherence.

Suggestions for further research include a qualitative research design to explore coping strategies for patients with grade two and grade three hypertension, especially in return to religion variables and suppression of competing activities. Practice implications for this research is to increase drug adherence for patient hypertension grade two and grade three, strengthened coping strategies are very important.

\section{FUNDING SOURCE}

Sources of funding come from STIKes Kepanjen (Kepanjen College of Health Science) and Kemenristek Dikti (Ministry of Research and Higher Education).

\section{ACKNOWLEDGEMENT}

The author would like to thank STIKes Kepanjen Malang and Airlangga University for their support in conducting this research.

\section{REFERENCES}

Atiim, G. A., \& Elliott, S. J. (2015). The Global Epidemiologic Transition: Noncommunicable Diseases and Emerging Health Risk of Allergic Disease in Sub-Saharan Africa. Health Education and Behavior, 43, 37S-55S. https://doi.org/10.1177/1090198115606918

Bell Kayce,Twiggs june and Olin Bernie R. 2015.Hypertension : The Silent Killer: Updated JNC8 Guideline Recommendations. Alabama Pharmacy Association

Bhagani, S., Kapil, V., Lobo, M. D. (2018). Hypertension. Medicine. 46 (9), 509-515. https://doi.org/10.1016/j.mpmed.2018.06.009

Biggs, A., Brough, P., Drummond, S. (2017). The Handbook of Stress and Health: A Guide to Research and Practice, First Edition. Edited by Cary L. Cooper and James Campbell Quick. John Wiley \& Sons, Ltd.

Borghi, C., Tubach, F., Backer, G. De, Dallongeville, J., Guallar, E., Medina, J., ... Halcox, J. P. (2016). Lack of control of hypertension in primary cardiovascular disease prevention in Europe: Results from the EURIKA study is. International Journal of Cardiology, 218, 83-88. https://doi.org/10.1016/i.ijcard.2016.05.044

Büssing, A., Pilchowska, I., \& Surzykiewicz, J. (2015). Spiritual Needs of Polish Patients with Chronic Diseases. Journal of Religion and Health, 54(5), 1524-1542. https://doi.org/10.1007/s10943014-9863-x

Büssing, A., Janko, A., Baumann, K., Hvidt, N. C., \& Kopf, A. (2013a). Spiritual needs among patients withchronic pain diseases and cancer living in a secular society.Pain Medicine, 14, 1362-1373.

Büssing, A., \& Koenig, H. G. (2010). Spiritual needs of patients with chronic diseases. Religions, 1(1), 1827. https://doi.org/10.3390/rel1010018

Carver, C. S. (2013). COPE Inventory : Measurement Instrument Database for the Social Science.

Drutchas, A., \& Anandarajah, G. (2014). Spirituality and coping with chronic disease in pediatrics. Rhode Island Medical Journal (2013), 97(3), 26-30.

Fikriana, R. (2016). Faktor - faktor yang diduga menjadi prediktor terjadinya peningkatan tekanan darah sistolik pada penderita hipertensi, Jurnal Kesehatan Mesencephalon, 2(4), 285-291 http://dx.doi.org/10.36053/mesencephalon.v2i4 .14

Fikriana, R., \& Devy, S. R. (2018). The effect of age and body mass index on blood glucose, blood cholesterol, and blood pressure in adult woman. Indian Journal of Public Health Research \& Development, https://doi.org/10.5958/09765506.2018.01687.X

Fikriana, R. (2018). Sistem Kardiovaskuler. Yogyakarta : Deepublish

Han, Hae-Ra., Lee, H., Commodore-Mensah, Y., Kim, M. (2014). Development and Validation of the hypertension self care profile : a practical tool to measure hypertension self care. Journal of Cardiovascular Nursing. doi:10.1097/JCN.0b013e3182a3fd46

29(3)

Granger, B. B., Ekman, I., Granger, C. B., Ostergren, J., Olofsson, B., Michelson, E., ... Swedberg, K. (2009). Adherence to medication according to sex and age in the CHARM programme. European Journal of 
Heart Failure, 11(11), 1092-1098. doi:10.1093/eurjhf/hfp142

Hernández-ledesma, A. L., Rodríguez-méndez, A. J., Gallardo-vidal, L. S., Trejo-cruz, G., García-solís, P., Dávila-esquivel, F. D. J., ... Querétaro, A. De. (2018). Coping strategies and quality of life in Mexican multiple sclerosis patients: Physical, psychological and social factors relationship. Multiple Sclerosis and Related Disorders, 25(May), 122-127. https://doi.org/10.1016/j.msard.2018.06.001

Indonesian Society of Hypertension. (2019). Konsensus Penatalaksanaan Hipertensi 2019. Jakarta : InaSH

Kemenkes RI. (2013). Riset Kesehatan Dasar. Jakarta: Kemenkes RI. 88-90

Kemenkes RI. (2018). Laporan Nasional Riskesdas 2018. Jakarta: Kemenkes RI. 154-66

Nursalam. (2017). Metodotogi Penelitian Ilmu Keperawatan : Pendekatan Praktis Edisi 4. Jakarta : Salemba Medika

Manteuffel, M., Williams, S., Chen, W., Verbrugge, R. R., Pittman, D. G., \& Steinkellner, A. (2014). Influence of patient sex and gender on medication use, adherence, and prescribing alignment with guidelines. Journal of Women's Health, 23(2), 112119. https://doi.org/10.1089/jwh.2012.3972

Nursalam, N., Dwi, O.D.W., Alit, A.N.K., Ferry, E. (2018). Analysis of the stressor and coping strategies of adolescents with dysmenorrhoea. Indian Journal of Public Health Research \& Development, $\quad 9(10), \quad 381-386$. https://doi.org/10.5958/09765506.2018.01373.6

Orzechowska, A., Zajaczkowska, M., Talarowska, M., \& Gałecki, P. (2013). Depression and ways of coping with stress: A preliminary study. Medical Science Monitor, 19, 1050-1056. https://doi.org/10.12659/MSM.889778

Perricone, G., Guerra, M. P., Cruz, O., Polizzi, C., Lima, L., Morales, M. R., ... Fontana, V. (2013). Maternal coping strategies in response to a child's chronic and oncological disease: A cross-cultural study in Italy and Portugal. Pediatric Reports, 5(2), 43-47. https://doi.org/10.4081/pr.2013.e11

Ramli, A., Ahmad, N. S., \& Paraidathathu, T. (2012). Medication adherence among hypertensive patients of primary health clinics in Malaysia. Patient Preference and Adherence, 6, 613-622. https://doi.org/10.2147/PPA.S34704

Rohman., Nursalam., Titin, S., Ali, A.R. (2019). The relationship between knowledge and spirituality with the prevention behavior of infection transmission in PLWHA. Indian Journal of Public Health Research \& Development, 10(8), 2817$2822 . \quad$ https://doi.org/10.5958/09765506.2019.02300.3

Shafi, S. T., \& Shafi, T. (2017). Journal of Epidemiology and Global Health A survey of hypertension prevalence, awareness, treatment, and control in health screening camps of rural central Punjab , Pakistan. Journal of Epidemiology and Global Health, 7(2), 135-140. https://doi.org/10.1016/i.jegh.2017.01.001

Visutyothin, Y., \& Boonmongkon, P. (2018). Selfregulating blood sugar control in women with uncontrolled diabetes mellitus. Kasetsart Journal of Social Sciences, 1-5. https://doi.org/10.1016/j.kjss.2017.12.016 